\title{
Registries for paediatric pulmonary hypertension
}

\author{
Georg Hansmann ${ }^{1}$ and Marius M. Hoeper²
}

Affiliations: 'Dept of Paediatric Cardiology and Critical Care, Hannover Medical School, Hannover, ${ }^{2}$ Dept of Respiratory Medicine, Hannover Medical School, Hannover, Germany.

Correspondence: G. Hansmann, Dept of Paediatric Cardiology and Critical Care, Hannover Medical School, Carl-Neuberg-Str. 1, 30625 Hannover, Germany: E-mail: hansmann.georgamh-hannover.de

0 @ERSpublications

Paediatric pulmonary arterial hypertension should be treated specifically and differently from adult pulmonary arterial hypertension http://ow.ly/mzPDT

Pulmonary arterial hypertension (PAH) is a progressive, angio-obliterative disease leading to increased pulmonary vascular resistance, right heart failure, and death in $\sim 25-60 \%$ of PAH patients 5 years after diagnosis [1-3]. The estimated prevalence of PAH is $15-50$ cases per million adults [4-6] and 2-16 cases per million children [7-9]. In certain at-risk groups, however, the occurrence of PAH is substantially higher. For example, the prevalence is $0.5 \%$ in HIV-infected patients [10] and 4-6\% in schistosomiasis [11]. These diseases are far more common in developing countries with limited health care and, thus, the real burden of $\mathrm{PAH}$ worldwide is probably underestimated.

Historically, extrapolation from adult pulmonary hypertension studies has been used to make assumptions on the disease in children; however, this approach is neither validated nor appropriate [12]. The recent comprehensive analysis of paediatric registries allowed predictions on the epidemiology, clinical practice and outcome of PAH in childhood. In France, for example, the prevalence of paediatric PAH was estimated to be 2.2 cases per million children [7]. In the UK, the incidence and prevalence of idiopathic PAH (IPAH) was 0.48 and 2.1 per million children, respectively [8]. In the Netherlands, the incidence and prevalence of IPAH was 0.7 and 4.4 per million children, whereas PAH associated with congenital heart disease (PAHCHD) had an incidence of 2.2 and prevalence of 15.6 per million [9]. Of note, the PAH disease spectrum may somewhat differ in the individual tertiary centre and in multicentre registries [13]. In a British cohort study, the 5-year survival for children with IPAH was only $75 \%$ with a freedom from death or transplantation of only 57\% (1986 and 2000 with follow-up to 2007) [8].

Patients, family members and healthcare providers should be aware of the unique features of paediatric pulmonary hypertensive vascular disease (PPHVD) [14, 15]. These include the fetal origins, developmental and adaptive aspects of pulmonary vascular disease (PVD) and right ventricular dysfunction (RVD) in both childhood- and adult-onset disease. The proposal for a new classification of PPHVD (Panama, 2011 [14]) aims to incorporate such specific paediatric aspects that are not adequately addressed in the current classification of pulmonary hypertension (Dana Point, CA, USA, 2008) [16]. The Panama proposal of PPHVD is still very new, not broadly (internationally) accepted yet, and probably will undergo further modifications, according to international meetings (e.g., the PH World Symposium, Nice, France, 2013) and feedback from healthcare providers.

Received: April 132013 | Accepted after revision: May 012013

Support statement: G. Hansmann has been supported by the American Heart Association (AHA)/Pulmonary Hypertension Association (grant $0425943 \mathrm{H}$ ), the German Interdisciplinary Association of Critical Care Medicine (DIVI), and the German Children's Heart Foundation (Stiftung KinderHerz).

Conflict of interest: Disclosures can be found alongside the online version of this article at www.erj.ersjournals.com 
PAH associated with congenital heart disease (CHD) is most commonly diagnosed in childhood. It is important to distinguish between CHD/left-to-right shunts with PVD (i.e., PPHVD) and without PVD, because the latter PAH group benefits the most and primarily from shunt closure, be it interventionally or surgically. In addition, in single versus biventricular circulations, PAH haemodynamics and physiology differ remarkably. While adults with Eisenmenger-PAH have a better survival than those with idiopathic/ heritable PAH, children with PAH-CHD have a 5-year mortality that appears to be comparable to those with idiopathic/heritable PAH (29 versus 25\%) [17]. The severity of adult PAH-CHD tends to be underestimated because adult patients probably represent a selection of "survivors".

Interestingly, the sex ratio in prepubertal children with PAH is nearly even whereas $70-80 \%$ of adult patients with PAH are female. Potential environmental risk factors and disease modifiers such as cigarette smoke exposure [18], hormonal and metabolic abnormalities such as hyperandrogenaemia, dyslipidaemia and insulin resistance $[19,20]$, have been identified in adults with PAH recently, and should be studied systematically in children. However, sufficient recruitment of PAH children into classical randomised controlled trials (RCTs) is particular difficult. The challenging combination of an orphan disease with a complex, heterogeneous pathobiology has led to the search for alternative study modalities versus the traditional RCTs in PAH (i.e. "adaptive trial designs" [21]) although even those face the problem of sufficient recruitment.

Registries have become an important source of information in adult PAH (REVEAL (Registry to Evaluate Early And Long-term PAH Disease Management) [22], French Registry [23], COMPERA (Prospective Registry of Newly Initiated Therapies for Pulmonary Hypertension) [24], and more recently also in paediatric PAH (e.g., REVEAL: survival in paediatric PAH [17]). The Tracking Outcomes and Practice in Paediatric Pulmonary Hypertension (TOPP) registry is a prospective registry that provides information on demographics, diagnostic evaluation, treatment and outcomes in paediatric pulmonary hypertension [25]. The recent TOPP analysis (31 centres in 19 countries; 2008-2010) identified important clinical features specific to the care of paediatric pulmonary hypertension, which drew attention to the need for paediatric data rather than extrapolation from adult studies [25]. In total, 317 of 362 pulmonary hypertension patients had PAH (PH Group 1, 88\%), which was idiopathic or familial PAH in 182 (57\%), and associated with other disorders in 135 (43\%), of which 115 (85\%) cases were associated with congenital heart disease. $42(12 \%)$ patients had pulmonary hypertension associated with respiratory disease/hypoxaemia, with bronchopulmonary dysplasia being most frequent. Although such pulmonary hypertension registries are limited by the lack of randomisation, proper control groups and causal conclusions, they do yield very valuable information for the practicing physician.

In this issue of the ERJ, BEGHETTI et al. [26] (the TOPP registry investigators) report that most children with pulmonary hypertension (defined according to the Venice classification, 2003 [27]) do not undergo the diagnostic work-up recommended for adults, pointing towards the inappropriateness of adult guidelines for children and/or the incomplete awareness of the current guidelines for adults with pulmonary hypertension, or both. For example, brain natriuretic peptide (BNP) and N-terminal prohormone of BNP testing was performed in $<25 \%$ of children with pulmonary hypertension, and the 6-min walk test and cardiopulmonary exercise testing were conducted in only 38 and $7 \%$ patients, respectively. Both exercise tolerance tests are probably not reliable in children $<8$ years of age and those with developmental delay, e.g., in trisomy 21 (13\% in TOPP [25]). Hence, these functional variables do not serve well as (the sole) primary outcome in paediatric RCTs.

BeGHetTi et al. [26] (TOPP registry) also report on the safety of invasive haemodynamic assessment in children with pulmonary hypertension and found that 7\% (37 out of 554) of patients at diagnosis had significant complications within $24 \mathrm{~h}$ after heart catheterisation, including new inotropic support (3\%, 14 out of 554), pulmonary hypertensive crisis $(2 \%, 10$ out of 554$)$ and cardiac arrest $(0.9 \%, 5$ out of 554). For the total number of heart catheterisations $(n=908)$ performed at diagnosis $(n=554)$ and follow up $(n=354)$, complications including pulmonary hypertensive crises, need for inotropic support and cardiac arrest were reported in 5.9\% of cases; and there were five cases of procedure-related deaths [26]. The complication rate for cardiac catheterisation with or without anaesthesia is apparently higher in children than in adults [28], reminding us that we must weigh the risks and benefits of invasive procedures in this fragile patient population and that that the care of children with PAH belongs in experienced hands. Nevertheless, cardiac catheterisation with vasodilator testing remains an essential part of the comprehensive PAH work-up at diagnosis.

An expert statement on adult pulmonary hypertension has been published by the American Heart Association and the American College of Cardiology in 2009 [29]. The European Respiratory Society and the European Society of Cardiology have published guidelines for the diagnosis and treatment of adult pulmonary hypertension in the same year [30]. Future guidelines on paediatric pulmonary hypertension 
and RVD need to address the specifics of the disease in paediatric populations as well as concomitant disorders, expert clinical evaluation and future therapies [31, 32].

In summary, children are not simply young adults and $\mathrm{PAH}$ in children differs from PAH in adults. Physician scientists will need to determine the genetic, circulatory and environmental risk factors and disease modifiers of pulmonary vascular disease and right ventricular dysfunction, thus striving for "individual risk assessment", "diagnostic evaluation" including better biomarkers, "clinical staging", and "tailored therapy" of patients with PAH. The unique features and uncertainties of childhood PVD and RVD are evident and underline the need for significant and specific basic and translational research efforts, in addition to paediatric registries and clinical networks.

\section{References}

1 McLaughlin VV, Presberg KW, Doyle RL, et al. Prognosis of pulmonary arterial hypertension: ACCP evidencebased clinical practice guidelines. Chest 2004; 126: 78S-92S.

2 Voelkel NF, Gomez-Arroyo J, Abbate A, et al. Pathobiology of pulmonary arterial hypertension and right ventricular failure. Eur Respir J 2012; 40: 1555-1565.

3 Lee WT, Ling Y, Sheares KK, et al. Predicting survival in pulmonary arterial hypertension in the UK. Eur Respir J 2012; 40: 604-611.

4 Humbert M, Sitbon O, Chaouat A, et al. Pulmonary arterial hypertension in France: results from a national registry. Am J Respir Crit Care Med 2006; 173: 1023-1030.

5 Peacock AJ, Murphy NF, McMurray JJ, et al. An epidemiological study of pulmonary arterial hypertension. Eur Respir J 2007; 30: 104-109.

6 Escribano-Subias P, Blanco I, Lopez-Meseguer M, et al. Survival in pulmonary hypertension in Spain: insights from the Spanish registry. Eur Respir J 2012; 40: 596-603.

7 Fraisse A, Jais X, Schleich JM, et al. Characteristics and prospective 2-year follow-up of children with pulmonary arterial hypertension in France. Arch Cardiovasc Dis 2010; 103: 66-74.

8 Moledina S, Hislop AA, Foster H, et al. Childhood idiopathic pulmonary arterial hypertension: a national cohort study. Heart 2010; 96: 1401-1406.

9 van Loon RL, Roofthooft MT, Hillege HL, et al. Pediatric pulmonary hypertension in the Netherlands: epidemiology and characterization during the period 1991 to 2005. Circulation 2011; 124: 1755-1764.

10 Sitbon O, Lascoux-Combe C, Delfraissy JF, et al. Prevalence of HIV-related pulmonary arterial hypertension in the current antiretroviral therapy era. Am J Respir Crit Care Med 2008; 177: 108-113.

11 Lapa M, Dias B, Jardim C, et al. Cardiopulmonary manifestations of hepatosplenic schistosomiasis. Circulation 2009; 119: 1518-1523.

12 Barst RJ, Ertel SI, Beghetti M, et al. Pulmonary arterial hypertension: a comparison between children and adults. Eur Respir J 2011; 37: 665-677.

13 Levy M, Celermajer D, Szezepanski I, et al. Do tertiary paediatric hospitals deal with the same spectrum of paediatric pulmonary hypertension as multicentre registries? Eur Respir J 2013; 41: 236-239.

14 Cerro MJ, Abman S, Diaz G, et al. A consensus approach to the classification of pediatric pulmonary hypertensive vascular disease: Report from the PVRI Pediatric Taskforce, Panama 2011. Pulm Circ 2011; 1: 286-298.

15 Lammers AE, Adatia I, Cerro MJ, et al. Functional classification of pulmonary hypertension in children: Report from the PVRI pediatric taskforce, Panama 2011. Pulm Circ 2011; 1: 280-285.

16 Simonneau G, Robbins IM, Beghetti M, et al. Updated clinical classification of pulmonary hypertension. J Am Coll Cardiol 2009; 54: S43-54.

17 Barst RJ, McGoon MD, Elliott CG, et al. Survival in childhood pulmonary arterial hypertension: insights from the registry to evaluate early and long-term pulmonary arterial hypertension disease management. Circulation 2012; 125: $113-122$.

18 Weissmann N, Grimminger F, Seeger W. Smoking: Is it a risk factor for pulmonary vascular diseases? Pulm Circ 2012; 2: 395-396.

19 Zamanian RT, Hansmann G, Snook S, et al. Insulin resistance in pulmonary arterial hypertension. Eur Respir J 2009; 33: 318-324.

20 Heresi GA, Aytekin M, Newman J, et al. Plasma levels of high-density lipoprotein cholesterol and outcomes in pulmonary arterial hypertension. Am J Respir Crit Care Med 2010; 182: 661-668.

Rich S. Future of clinical trials for pulmonary hypertension. Circulation 2011; 123: 2919-2921.

22 Benza RL, Miller DP, Gomberg-Maitland M, et al. Predicting survival in pulmonary arterial hypertension: insights from the Registry to Evaluate Early and Long-Term Pulmonary Arterial Hypertension Disease Management (REVEAL). Circulation 2010; 122: 164-172.

23 Humbert M, Sitbon O, Yaici A, et al. Survival in incident and prevalent cohorts of patients with pulmonary arterial hypertension. Eur Respir J 2010; 36: 549-555.

24 Hoeper MM, Huscher D, Ghofrani HA, et al. Elderly patients diagnosed with idiopathic pulmonary arterial hypertension: Results from the COMPERA registry. Int J Cardiol 2012; [In press DOI: 10.1016/j.ijcard.2012.10.026].

25 Berger RM, Beghetti M, Humpl T, et al. Clinical features of paediatric pulmonary hypertension: a registry study. Lancet 2012; 379: 537-546.

26 Beghetti M, Berger RMF, Schulze-Neick I, et al. Diagnostic evaluation of pediatric pulmonary hypertension in current clinical practice. Eur Respir J 2013; 42: 689-700.

27 Simonneau G, Galie N, Rubin LJ, et al. Clinical classification of pulmonary hypertension. J Am Coll Cardiol 2004; 43: $5 \mathrm{~S}-12 \mathrm{~S}$.

28 Hoeper MM, Lee SH, Voswinckel R, et al. Complications of right heart catheterization procedures in patients with pulmonary hypertension in experienced centers. J Am Coll Cardiol 2006; 48: 2546-2552.

29 McLaughlin VV, Archer SL, Badesch DB, et al. ACCF/AHA 2009 expert consensus document on pulmonary hypertension: a report of the American College of Cardiology Foundation Task Force on Expert Consensus 
Documents and the American Heart Association: developed in collaboration with the American College of Chest Physicians, American Thoracic Society, Inc., and the Pulmonary Hypertension Association. Circulation 2009; 119: 2250-2294.

30 Galie N, Hoeper MM, Humbert M, et al. Guidelines for the diagnosis and treatment of pulmonary hypertension. Eur Respir J 2009; 34: 1219-1263.

31 Rhodes CJ, Davidson A, Gibbs JS, et al. Therapeutic targets in pulmonary arterial hypertension. Pharmacol Ther 2009; 121: 69-88.

32 Archer SL, Weir EK, Wilkins MR. Basic science of pulmonary arterial hypertension for clinicians: new concepts and experimental therapies. Circulation 2010; 121: 2045-2066. 